\title{
A Rare Case of Placenta Accreta Presenting as Placental Polyp
}

${ }^{1}$ Rama Garg, ${ }^{2}$ Parneet Kaur, ${ }^{3}$ Namita Chopra

\begin{abstract}
Placental polyp is an intrauterine polypoidal or pedunculated mass of placental tissue retaining for an indefinite period after delivery or abortion. Because of its rarity, the literature contains few references, and there are great varieties not only on its diagnosis but also the management. We present a rare case of placenta accreta presenting as a uterine polyp. This is the only one case diagnosed at our hospital and managed conservatively.
\end{abstract}

Keywords: Myometrium, Placenta accreta, Placental polyp.

How to cite this article: Garg R, Kaur P, Chopra N. A Rare Case of Placenta Accreta Presenting as Placental Polyp. J South Asian Feder Obst Gynae 2018;10(Suppl 1):361-363.

Source of support: Nil

Conflict of interest: None

Date of received: 27 November 2015

Date of acceptance: 12 March 2018

Date of publication: July 2019

\section{INTRODUCTION}

Placental polyp is a somewhat pedunculated remnant of chorionic tissue retained in the uterine cavity for an indefinite time. It may result in abnormal uterine bleeding and slightly elevated detectable titers of serum $\beta$-human chorionic gonadotropin ( $\beta-\mathrm{hCG})$. These pedunculated masses of villi are often found within days to weeks following abortion or delivery of term placenta. However, they rarely persist for months or even years after pregnancy. Since, trophoblastic neoplasms especially placental site trophoblastic tumor may have similar symptoms and signs, itis important to consider placental polyp in the differential diagnosis in such situations. ${ }^{1}$

A placental polyp is an intrauterine polypoid or pedunculated mass of placental tissue retaining for an indefinite period after delivery or abortion. Because of its rarity, the literature contains few references, and there are great varieties not only on its diagnosis but also the management. ${ }^{2}$ This is the only one case diagnosed at our

${ }^{1}$ Associate Professor, ${ }^{2}$ Professor, ${ }^{3}$ Junior Resident

${ }^{1-3}$ Department of Obstetrics and Gynecology, Government Medical College, Patiala, Punjab, India

Corresponding Author: Rama Garg, Associate Professor, Department of Obstetrics and Gynecology, Government Medical College, Patiala, Punjab, India, e-mail: drramagarg@gmail.com hospital till now. The intriguing clinical course is reported and discussed below

\section{CASE DISCRIPTION}

A 30 years old female Krishna with CR no. 12306 was admitted in an emergency in Department of Obstetrics and Gynecology, Rajindra Hospital, Patiala on 30th July 2015 at $7.00 \mathrm{pm}$. She was referred to as a case of puerperal sepsis with severe anemia and had two units of blood transfused in the periphery. She came as P3L1 with a complaint of bleeding per vaginum, since 10 days, moderate in amount, intermittent, associated with the passage of blood clots. There was no associated pain abdomen. No history of any obvious precipitating factor like trauma or coitus. There was a history of low-grade fever for 2 days, intermittent, not associated with chills and rigors, not associated with nausea or vomiting, altered bowel habits, urinary complaints or chest complaints. She gave a history of normal vaginal delivery at full term on 22nd June 2015 in a private hospital in Kaithal, Haryana. A single male baby was born with birth weight $2.5 \mathrm{~kg}$ (according to the patient), died immediately after birth (cause not known to patient and relatives and record not available). No history of antepartum, intrapartum or immediate postpartum hemorrhage. No history of instrumental delivery. According to the patient, the postpartum period was uneventful. Bleeding per vaginum lasted for 15-17 days postpartum and was within normal limits.

The patient had one normal vaginal delivery 5 years back (male baby, alive and healthy) followed by another normal vaginal delivery 2 years back (died on the 2 nd day of life). This was her third vaginal delivery.

At the time of admission, patient's vitals were stable, chest clear, a urine pregnancy test was negative. The patient was pale, ( $\mathrm{Hb} 6 \mathrm{~g} \%$ ) abdomen was soft, nontender. On per speculum examination, cervical os was open and a friable polypoidal mass of 5 to $6 \mathrm{~cm}$ seen protruding through the os (Fig. 1). The foul-smelling discharge was present.

On per vaginum examination, cervical os was open (1 finger loose), and a 5-6 cm friable polypoidal mass with a thick smooth pedicle of $2-2.5 \mathrm{~cm}$ diameter coming from inside the uterine cavity was seen with cervix felt all around. On sounding the uterine cavity was 3 inches 


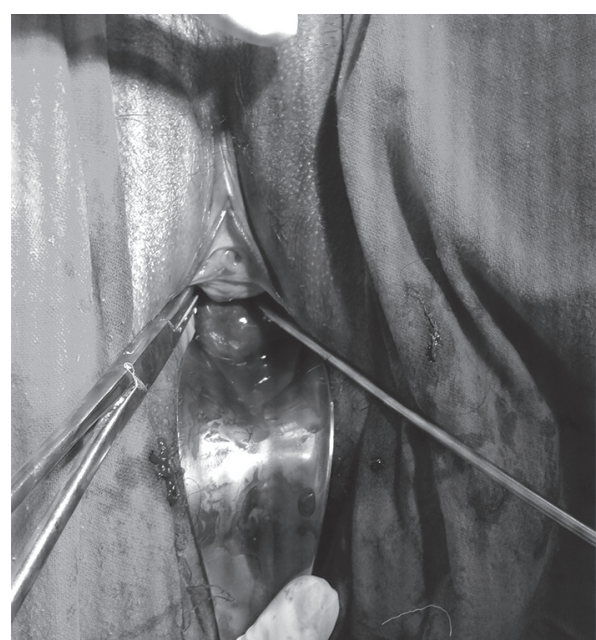

Fig. 1: Placental polyp extruding out of external os

in length, so inversion was ruled out. A biopsy was taken from the protruding mass and sent for histopathology on 31/7/2015. Vaginal packs were put in, and injectable antibiotics and hemostatic (tranexamic acid) started. Four packs of red blood cells were transfused during her hospital stay and the patient was observed for fresh bleeding. She was planned for examination under anesthesia and hysteroscopy polypectomy. A provisional diagnosis of a placental polyp or placental site trophoblastic tumor was made. Serum beta HCG levels were $0.55 \mathrm{IU} / \mathrm{L}$. Histopathology report of biopsy of the mass showed numerous chorionic villi with myxoid degeneration, areas of decidualization and hemorrhage. Bits of trophoblastic tissue also seen. All three types of trophoblastic cells (cytotrophoblast, syncytiotrophoblast and intermediate trophoblasts) could be seen. No evidence of atypia seen (Fig. 2). Postprocedure patients bleeding $\mathrm{p} / \mathrm{v}$ was under control. Transvaginal ultrasound and color Doppler study were done on $7 / 8 / 2015$.

It revealed uterus was retroverted, normal in dimensions and contour and suggestive of stretching in fundus and body. There was no evidence of echogenic material suggestive of a blood clot or retained products of conception in endometrial cavity. The endometrium was thin lined. Cervix was $4.2 \mathrm{~cm}$ in AP dimension. There was a well-defined heterogeneous mass of $2.9 \times 2.3 \times$ $2.7 \mathrm{~cm}$ size in the cervical region with hypoechoic areas within it. Few echogenic specks with dirty shadowing in a small peripheral area, (maybe air locules) seen. There was visualized a linear vascular feeder vessel extending up to and into this mass showing spectral waveform corresponding to uterine artery and extending caudally from anterior myometrium's superior aspect. Provisional diagnosis made by radiologist was decidual pseudo polyp or placental site trophoblastic nodule or other pathology.

Immunohistochemistry using antibodies against human placental lactogen and MRI could not be done as

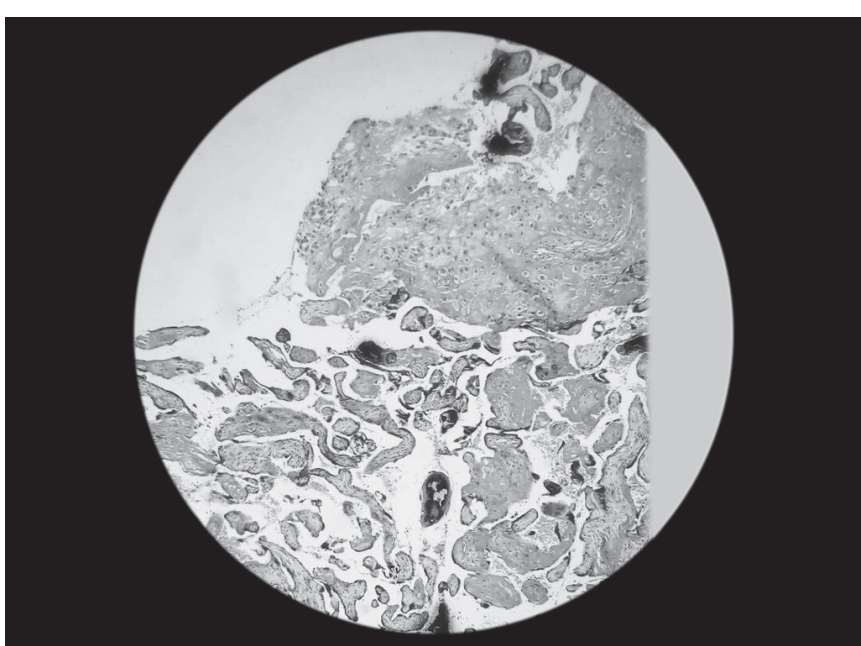

Fig. 2: Biopsy from mass showing chorionic villi with myxoid degeneration, decidualization and hemorrhage. Bits of trophoblastic tissue and calcification seen. (H\&E staining; 10x)

the patient could not afford it. On 11th August 2015, she expelled some tissue about $4 \times 4 \mathrm{~cm}$ in the bathroom with $\mathrm{BPV}$ which was not excessive.

The patient was taken to OT for EUA and hysteroscopic polypectomy on 13th August 2015 with preparation for emergency hysterectomy in case of massive hemorrhage, as facilities for uterine embolization are not available in our institute.

There was a polyp $3 \times 3 \mathrm{~cm}$ (reduced in size as compared to initial findings and retracted back into the uterine cavity) at 10 o'clock to 3 o'clock position with a pedicle inside the uterine cavity. With sponge holding forceps, the polyp was gently avulsed and curettage is done (Fig. 3), followed by intrauterine and vaginal packing. Two specimens sent for histopathology, one containing polyp and the other containing the pedicle with adjoining endow-myometrium. Injectable antibiotics, hemostatic and uterotonics were continued. Postoperatively packs were removed 48 hours later gradually.

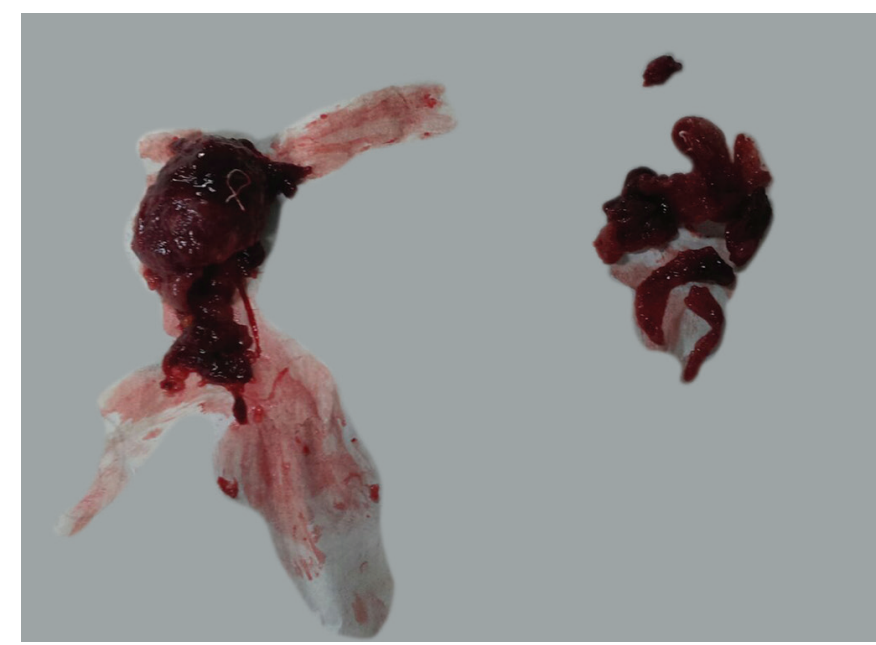

Fig. 3: Hysteroscopic removal of polyp and its pedical along with myometrium 


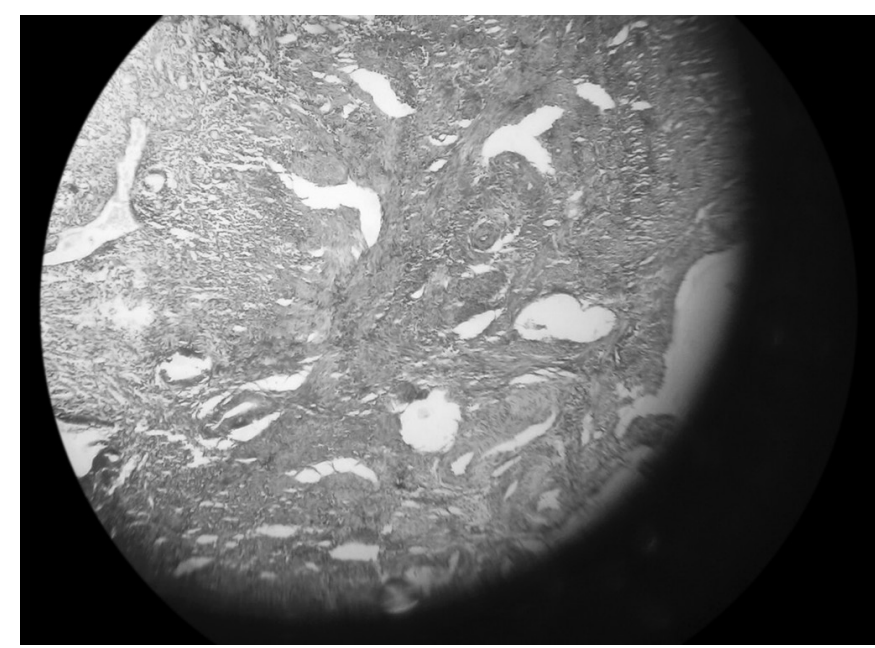

Fig 4: Endometrial glands in proliferative phase. Myometrium in its anterior $1 / 3$ rd showing focal decidualization, inflammatory infilterate and trophoblastic cells,consistent with placenta accreta. (H\&E staining; $10 \times$ )

Histopathology report showed endometrial glands in the proliferative phase, myometrium in its anterior one third showing focal decasualization, inflammatory infiltrate and occasional trophoblastic cells consistent with the finding of placenta accrete (Fig. 4).

The section from the polyp showed well-formed villous structures lined by trophoblastic tissue consistent with retained products of conception along with hemorrhage, necrosed tissue and acute and chronic inflammatory infiltrate.

The patient was discharged on request on 17/8/2015.

She reported back in OPD with $\mathrm{h} / \mathrm{o}$ heavy menstrual bleed for three consecutive cycles. Her $\beta$-hCG were within normal limits. Her last menstrual period was normal and the patient is still under observation.

\section{DISCUSSION}

The placental polyp is a rare entity, and its estimated incidence is around 1 in 40,000 to 60,000 deliveries. ${ }^{3}$ Our case presented 5 weeks after her last pregnancy. Our case was the first case reported from our institute.

Pathogenesis of the placental polyps has been explained by two major theories. According to the first theory, the placenta is attached to the cornual or fundal myometria and is easily retained as the myometrium in this region is thin and atonic. The second theory sug- gests that the placenta accreta leads to the retention of placental tissue as the villi in this condition are directly attached to the underlying myometrium due to the defective decidua, especially in the cornual region. Hence, the cornu or fundus becomes the most common sites for the placental polyps. ${ }^{3 .}$ In our case, the placental polyp was attached at the fundus from 10 to 3 o'clock wide origin, and the microscopic examination revealed trophoblastic villi invading the myometrium at the site of attachment of polyp. The factors responsible for the survival of these villi are still not clear however these surviving villi are responsible for the production of the hCG which was not elevated in our case in contrast to the cases in the literature. Histologically, the placental polyp contains predominantly the ghost villi which are hyalinized and necrotic, and without lining trophoblast. ${ }^{3}$

A hypervascular placental polyp may lead to severe hemorrhage that requires blood transfusions, interventional radiological procedures, hysteroscopic resection and even hysterectomy to control bleeding. Evaluation of neovascularization by multimodal imaging is potentially useful in the management of placental polyp in women who wish to preserve fertility. ${ }^{1}$

Uterine artery embolization followed by selective hysteroscopic removal for placental polyp has been reported in 13 patients to minimize bleeding and preserve future fertility by Takeuchi et al. ${ }^{4}$

\section{CONCLUSION}

Cases of placental polyp usually land up in hysterectomy. A proper preoperative diagnosis with accurate interpretation of imaging findings and satisfactory curettage or biopsy can prevent unnecessary hysterectomy as was in our case.

\section{REFERENCES}

1. Behnamfar F, Zadeh F M, et al. A case of placental polyp after normal vaginal delivery. J Res Med Sci 2014;19(7):680-682.

2. Watcharotone $W$, Leelaphatanadit $C$. Placental polyp: A case report. Sririaj Med J 2005;57(9):391-393.

3. Shanthi V, Rao NM, et al. Placental Polyp-A Rare Case Report. Turk Patoloji Derg 2015;31(1):77-79.

4. Takeuchi K, Sugimoto M, et al. Pregnancy outcome of uterine arterial embolization followed by selective hysteroscopic removal of a placental polyp. Acta Obstet Gynecol Scand 2007;86(1):22-25. 